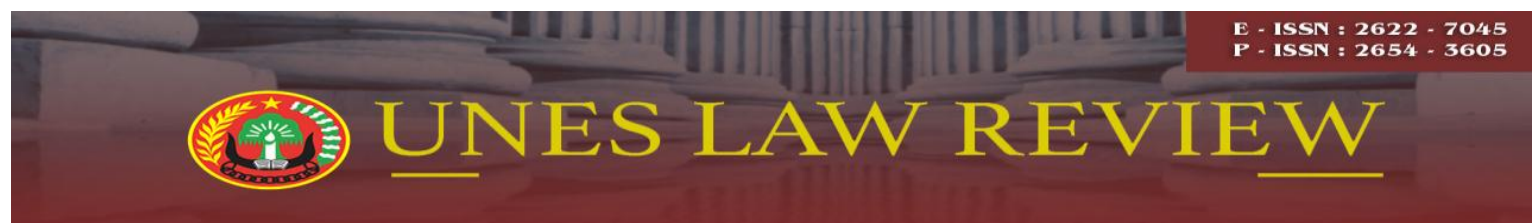

Email: uneslawreview@gmail.com

Online: http://review-unes.com/index.php/law

Volume 2, Issue 4, Juni 2020

\title{
PEMETAAN DAN ANALISA KONFLIK ANTARA MASYARAKAT DESA MENAMANG KIRI DAN PT SURYA HUTANI JAYA KABUPATEN KUTAI KARTANEGARA KALIMANTAN TIMUR
}

\author{
Naldi Gantika \\ Fakultas Hukum, Universitas Ekasakti, Padang, Indonesia \\ Email: hgantika74@gmail.com
}

\begin{abstract}
The urge for a peaceful and fair settlement of forestry conflicts also encourages business actors in the Indonesian forestry sector to develop conflict resolution mechanisms through dialogue and mediation processes through both mandatory (mandatory) and voluntary (voluntary) mechanisms. The commitment to apply the principle of FPIC (Free, Prior and Informed Consent) or free consent without coercion along its industrial supply chain (Supply Chain) has been declared by plantation companies under the banner of the APP (Asian Pulp and Paper) or Sinar Mas forestry (SMF) group and the APRIL group (Asia Pacific Resources International Limited). Not only that, the commitment to maintaining High Conservation Values contained in the company's work area was also expressed by the two major groups of players in the plantation forest industry in Indonesia. This condition has created opportunities for improved access and relations between the conflicting parties. In East Kalimantan, Conflict Mapping and Analysis was carried out in Menamang Kiri Village, Muara Kaman District, Kutai Kertanegara Regency. In the spatial mapping analysis that was carried out, part of the village of Menamang Kiri was within the concession of PT Surya Hutani Jaya (PT SRH), a wood supplier to APP. Mapping and Conflict Analysis is focused on extracting information related to governance and land management by PT SRH and the people of Menamang Kiri Village, conflicts or potential conflicts that arise and the parties involved, the perceptions of each party related to differences in interests, and policy analysis.
\end{abstract}

Kata Kunci: Konflik, Pemetaan, Kalimantan Timur

\section{PENDAHULUAN}

Keberadaan hutan di Indonesia selalu menjadi arena pertentangan antara para pihak yang berkepentingan terhadap sumber daya hutan. Dengan luas kawasan hutan seluas 124.002.848,67 hektar, hutan telah menjadi arena pertarungan kepentingan satu pihak dengan kepentingan pihak lainnya yang tak jarang saling berbenturan. Perbedaan dan pertentangan kepentingan yang paling menonjol adalah berkaitan dengan sistem tata kuasa/tata kelola lahan dan hutan serta sumber daya alam lainnya antara sistem tenurial yang dianut oleh masyarakat (Customary Tenure Systems) dengan sistem tenurial yang 
dianut oleh Negara (Statutory Tenure Systems). Pengakuan oleh pemerintah dengan beberapa syarat terhadap sistem tenurial yang dianut oleh masyarakat pada faktanya belum mampu memberikan solusi dan jalan keluar bagi penyelesaian konflik tenurial yang terjadi selama ini, terutama di dalam kawasan hutan.

Situasi ini kemudian mendorong terjadinya konflik kepentingan yang pada banyak kasus, berujung pada kekerasan. Dalam catatan Konsorsium Pembaharuan Agraria (KPA), pada akhir tahun 2013 terjadi peningkatan jumlah konflik dari 198 kasus di tahun 2012 menjadi 369 kasus di tahun 2013 (meningkat 86,36\%). Luasan areal konflik meningkat dari 318.248,89 hektar menjadi 1.281.660.09 hektar dan diantaranya adalah konflik di sektor kehutanan yang berjumlah 31 konflik dengan luas areal 545.258 hektar. Sementara Kementerian Kehutanan menyebutkan ada 33.000 desa yang berada dalam kawasan hutan dan harus dicarikan solusinya.

Penyelesaian konflik yang menggunakan pendekatan penegakkan hukum dengan bersandar pada UU No 41 Tahun 1999 Tentang Kehutanan terbukti tidak lah cukup untuk mengurai konflik di sektor kehutanan yang memiliki kompleksitas persoalan yang rumit dari sisi politik, ekonomi, sosial dan budaya. Meningkatnya konflik di sektor kehutanan telah menimbulkan dampak yang luas bukan saja bagi masyarakat tapi juga terhadap agenda pembangunan nasional dan dunia bisnis. Karena itu, upaya dan terobosanterobosan baru yang dilakukan oleh berbagai pihak terhadap penyelesaian konflik di sektor kehutanan terus menerus dikembangkan dan di implementasikan dalam tataran praktek. Dari sisi pemerintah, Nota Kesepakatan yang ditandatangani 12 Kementerian dan Lembaga tentang Rencana Aksi Bersama untuk percepatan pengukuhan kawasan hutan menunjukkan bahwa pemerintah mulai menyadari bahwa penyelesaian konflik sektor kehutanan sangatlah kompleks dan berkorelasi erat dengan kebijakan di sektor-sektor lain. Nota Kesepakatan yang lahir pada tanggal 11 Maret 2013 ini berisikan 3 pilar utama, dimana salah satu pilarnya menyatakan pentingnya Resolusi Konflik yang berlandaskan prinsip Keadilan dan Hak Asasi Manusia.

Desakan agar penyelesaian konflik kehutanan dilakukan secara damai dan berkeadilan ikut pula mendorong pelaku dunia usaha di sektor kehutanan Indonesia untuk mengembangkan mekanisme penyelesaian konflik melalui proses dialog dan mediasi baik melalui mekanisme mandatory (wajib) maupun voluntary (sukarela). Komitmen untuk 
menerapkan prinsip FPIC (Free, Prior and Informed Consent) atau persetujuan bebas tanpa paksaan disepanjang rantai pemasok industrinya (Supply Chain) telah dinyatakan oleh perusahaan hutan tanaman di bawah bendera grup APP (Asian Pulp and Paper) atau Sinar Mas forestry (SMF) dan grup APRIL (Asia Pacific Resources International Limited). Tidak hanya itu, komitmen untuk menjaga Nilai Konservasi Tinggi yang terdapat di dalam areal kerja perusahaan juga dinyatakan oleh dua grup besar pelaku utama industri hutan tanaman di Indonesia ini. Kondisi ini telah menciptakan peluang bagi perbaikan akses dan relasi antara pihak-pihak yang selama ini berkonflik. Karena itu, inisiatif-inisiatif tersebut patut diapresiasi.

Sebagai bagian dari kelompok masyarakat sipil, Imparsial Mediator Network (IMN) berusaha memberikan kontribusi dalam memperkuat komitmen-komitmen penyelesaian konflik yang berkeadilan dan menghargai Hak Asasi Manusia melalui penelitian tentang pemetaan dan analisa konflik di tempat-tempat dimana konflik sedang terjadi antara perusahaan dengan masyarakat adat dan lokal. Melalui penelitian tersebut, para pihak yang berkepentingan diharapkan dapat memahami aspek penting dalam pengelolaan konflik kehutanan sebagai basis untuk menjalankan komitmen keberlanjutan sosial dan lingkungan di sektor kehutanan.

\section{HASIL PENELITIAN DAN PEMBAHASAN}

\section{Konflik Kehutanan di Wilayah Desa Menamang Kiri}

Dalam konteks kajian konflik kehutanan yang terjadi di Desa Menamang Kiri dengan PT SHR, dilakukan analisis hubungan antara akses penguasaan terhadap sumber daya antara Perusahaan dengan masyarakat, penerapan kebijakan pengelolaan hutan dan pengaruhnya terhadap konflik pengelolaan hutan dengan pendekatan studi kasus (case study). Kedua, kasus konflik pengelolaan hutan di wilayah studi sudah dimulai sejak lama dan bersifat laten, namun tindakan antisipasi dan pencegahan yang dilakukan masih sangat minim, sehingga dalam hubungannya dengan persoalan ini diperlukan suatu analisa faktor structural bagi proses penyelesaian konflik di masa depan. Dalam kajian ini akan dilakukan analisis dengan menggunakan RaTa yang membantu untuk menjelaskan data dan fenomena yang diamati di lapangan. Identifikasi konflik, memaparkan kondisi konflik, 
dan memetakan para pihak atau aktor yang terlibat sekaligus peran mereka dalam hubungannya dengan konflik yang terjadi.

\section{Sejarah Konflik}

Seperti yang telah diuraikan pada BAB sebelumnya, dalam sejarahnya, warga telah berdiam diri diperkirakan ratusan tahun yang lalu sebelum masuknya perusahanperusahaan mengelola kawasan hutan Desa Menamang Kiri. Pembukaan lahan untuk pertanian dilakukan umumnya masih sebatas untuk memenuhi kebutuhan sendiri (subsistens) dan sebagian kecil saja apabila terdapat kelebihan dapat dijual. Sistem pembukaan lahan masih dilakukan oleh masyarakat secara tradisional yaitu dengan cara tebas, tebang, bakar dan tanam (slash and burn). Dengan sistem ini mereka dapat meningkatkan arus produksi dengan cara mengistirahatkan lahan-lahan yang sudah tidak lagi subur.

Konflik Tenurial yang terjadi di Desa Menamang Kiri merupakan gambaran dari persoalan yang umum terjadi dalam kaitannya dengan pengelolaan hutan di Kalimantan Timur, baik pada saat 'berhadapan' dengan HPH maupun HTI. Persoalan tenurial di Menamang Kiri dimulai ketika PT. Surya Hutani Jaya (PT SHR) mendapatkan di tahun 1996 pada "areal hutan" seluas 183.300 hektar. Pada waktu itu, PT SHR merupakan

bagian dari Sumalindo Group. Dalam perjalanan dan perkembangan Perusahaan, PT. Surya Hutani Jaya mengalami perubahan menejemen dimana ada keterkaitan kerjasama dalam GroupSumalindo kemudian di ambil alih sahamnya (60\%) oleh PT. Sinar Mas Forestry padatahun 2004 paska pencabutan izin operasional HTI melaui Surat Keputusan Menteri Kehutanan yang dikeluarkan pada tanggal 18 september 2002 atas 30 pemegang izin HTI termasuk karena disebabkan atas penilaian layak tehnis secara tehnis dan sejak itu diambil alih secara resmi oleh Sinar Mas group.

Dalam beberapa penelusuran dokumen media, konflik secara terbuka sudah dimulai sejak tahun 1996 antara warga Desa Menamang Kiri dan Menamang Kanan dengan PT SHR. Latar belakang kejadian ketika itu bermula ketika warga setempat menduduki base camp dan menyita seluruh alat berat berikut kantor itu pada tanggal 14 Oktober 1995. Hal itu terjadi karena warga Menamang merasa tidak puas terhadap ganti rugi tanaman masyarakat setempat oleh anak perusahaan PT. Sumalindo Group itu. 
Kemudian pada tanggal 13 januari 1996, terjadilah penganiayaan oleh tentara terhadap 14 warga. Dalam kejadian tersebut, 14 warga mengalami penganiayaan oleh militer. Modus pengusiran paksa yang dilakukan oleh tentara tersebut menggunakan dalih bahwa lokasi yang dikuasai warga merupakan tempat latihan perang. Dalam diskusi bersama warga, ganti rugi yang diterapkan pada waktu itu tidak sesuai dan yang menerima pun hanya sekitar 30\% dari jumlah warga di Desa Menamang Kiri yang lahannya juga digusur oleh PT SHR yang pada waktu itu lebih dikenal warga dengan sebutan PT Sumalindo (Group yang menguasai PT SHR). Karena trauma dengan kejadian tersebut, perlawanan masyarakat Desa Menamang Kiri surut.

Karena banyaknya lahan yang tidak digarap dan dikelola oleh PT Surya Hutani Jaya, pasca reformasi, masyarakat Desa Menamang Kiri mulai berani memasuki kembali wilayah kelolanya. Di tahun 2003-2004, masyarakat Desa Menamang Kiri mulai menggarap kembali lahan nya dengan berladang dan menanam tanaman buah-buahan. Meski demikian, di tahun 2004 tetap terjadi intimidasi yang dilakukan oleh aparat kepolisian (Brimob) ketika mengetahui masyarakat mulai menggarap lahan yang pernah berkonflik tersebut. Pak Abdul Wahab yang juga Ketua RT 5 Dusun Parang Biawak mengatakan sempat ditegur oleh aparat Brimob yang sedang melakukan patroli ketika sedang menggarap lahannya, tetapi aparat Brimob tersebut hanya menegur dan tidak disertai dengan ancaman fisik. Tuntutan tentang ganti rugi tanam tumbuh terus dilakukan warga kepada PT SHR sepanjang tahun 2006.

Di tahun 2008, terjadi kesepakatan antara PT SHR dengan masyarakat Desa Menamang Kiri yang dituangkan di dalam Akta Perjanjian Notaris BAKHTIAR, SH dengan Akta Berita Acara Kesepakatan PT Surya Hurai Jaya dengan Masyarakat Desa Menamang Kiri tanggal 24 Juli 2008, Nomor 343/2008/3 (tiga) rangkap, yang berkantor di Tenggarong Kutai Kartanegara Kalimantan Timur. Isi kesepakatan tersebut diantaranya adalah :

1. program sharing manfaat yang akan diberikan oleh PT Surya Hutani Jaya kepada masyarakat Desa Menamang Kiri sebesar Rp 100.000.000,- /tahun dan akan dievaluasi pada daur berikutnya (satu daur 6 tahun) terhitung dari tahun 2007 hingga 2008 adalah sebesar Rp 200.000.000,-

2. Memberikan uang bantuan kepada Desa Menamang Kiri untuk tahun 2008 sebesar Rp 100.000.000,- 
3. Desa dan masyarakat Menamang Kiri menjamin tidak ada lagi tuntutan tanam tumbuh dan lahan khususnya areal konsesi PT Surya Hutani Jaya

Dengan adanya kesepakatan tersebut maka konflik mulai mereda dan masyarakat terus berdampingan dengan PT Surya Hutani Jaya sampai munculnya konflik yang menurut masyarakat desa Menamang Kiri, bahwa PT Surya Hutani Jaya sudah inkar janji (wan prestasi) sebagaimana akta kesepakatan di Notaris Bakhtiar,SH. Munculnya konflik baru di antara PT Surya Hutani Jaya dengan Masyarakat Desa Menamang Kiri di akibatkan tidak lagi berjalannya kesepakatan antara PT Surya Hutani Jaya dengan Masyarakat Desa Menamang Kiri berkaitan dengan dana sharing manfaat sebesar Rp 100.000.000,-/tahun.

Sejak tahun 2009 hingga tahun 2014, dana sharing manfaat tidak diberikan oleh PT SHR. Hingga ada pertemuan dengan masyarakat desa menamang kiri di tahun 2009. Dari pertemuan itu PT Surya Hutani Jaya hanya mampu membayar dengan jumlah 43 Ton dari 150 ton/tahun dikarenakan PT. Surya Hutani Jaya menganggap lahan produksi HTI mulai tidak produktif lagi (berkurangnya hasil panen). Alasan pihak PT Surya Hutani Jaya tidak memenuhi prestasinya, karena dari hasil panen yang diharapkan per Ha-nya adalah Rp 150 Juta/Tahun, tetapi kenyataannya Pihak PT Surya Hutani Jaya merasa tidak mendapatkan sesuai dengan harapannya. Di tahun 2011, dilakukan pertemuan antara warga Desa Menamang Kiri dan PT SHR di kantor Camat Muara Kaman dengan difasilitasi oleh Dinas Kehutanan dan Perkebunan Pemerintah Kabupaten Kutai Kartanegara. Dalam pertemuan tersebut, masyarakat Desa Menamang Kiri menginginkan agar perusahaan mematuhi kesepakatan yang telah dibuat, dan disisi yang lain PT SRH bersikukuh untuk tetap membayar dana sharing manfaat dengan perhitungan pembayaran 43 ton/tahun. Menurut masyarakat, PT SHR juga tidak menjelaskan rincian dari perhitungan 43 ton/tahun tersebut. Pertemuan ini tidak membuahkan hasil karena masing-masing pihak bertahan pada posisinya masing-masing. Jika tidak ditangani dengan baik, potensi konflik terbuka akan muncul seperti halnya kejadian di tahun 1996.

\section{Objek Sengketa dan Klaim Para Pihak}

Dari uraian sebelumnya, dapat dijelaskan bahwa konflik yang terjadi pada mulanya karena adanya perbedaan persepsi dan kepentingan atas objek yang sama, yakni tanah. Tata kuasa dan tata kelola masyarakat tidak memiliki kekuatan dalam hukum formal 
Negara yang mengakui hak atas tanah berdasarkan sertifikat tanah yang dikeluarkan oleh BPN. Hal ini tidak terlepas dari sistem penguasaan dan pengelolaan kawasan hutan oleh Negara yang mengabaikan kepentingan dan kebutuhan masyarakat yang terkena dampak dari aktivitas industri kehutanan. Selain itu, pelanggaran atas kesepakatan antar pihak yang pernah dibuat, membuat objek yang disengketakan bertambah.

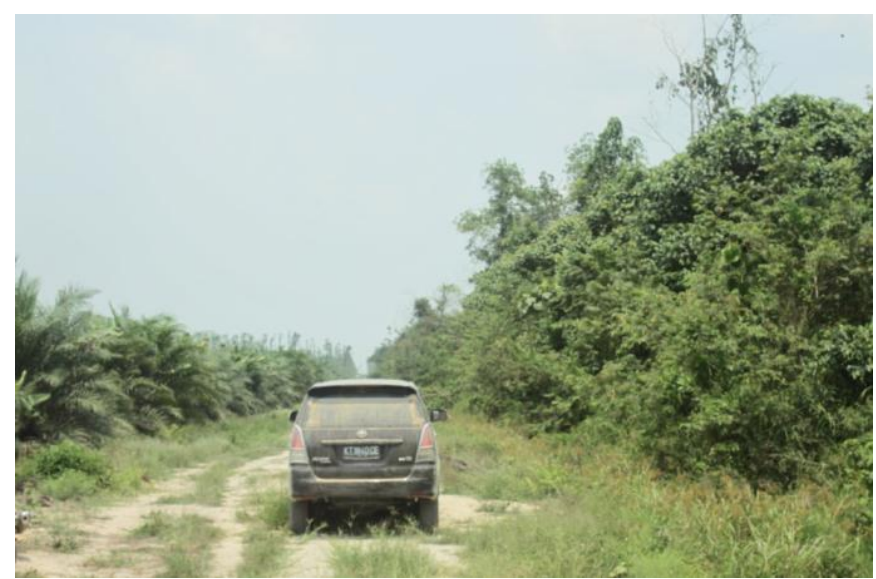

Gambar 1. Batas klaim warga dengan PT SRH dengan titik koordinat lapangan $\mathrm{N} 00^{0} 18^{\prime}$ 51,5 " dan E $116^{0} 55^{\prime} 42,1^{\prime \prime}$ '

Tabel 1. Klaim pihak yang berkonflik terhadap objek yang disengketakan

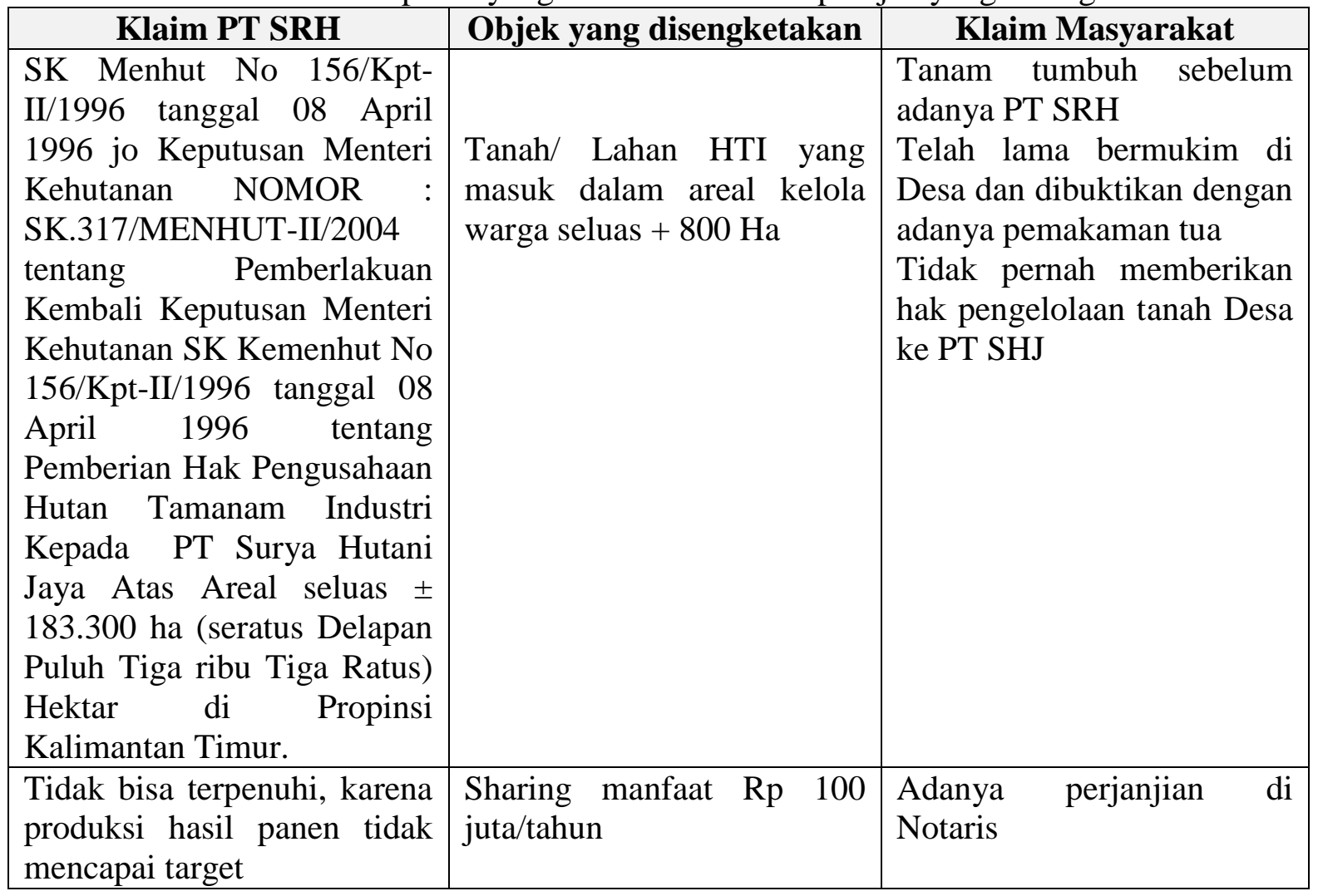


Tabel diatas menunjukkan klaim PT SRH bersandarkan pada perizinan yang dikeluarkan oleh Negara. Sedangkan klaim masyarakat hanya ditunjukkan oleh bukti fisik yang ada dilapangan, bukan berdasarkan dokumen resmi dari Negara. Perbedaan tentang konsep tata kuasa dan tata kelola inilah yang kemudian menimbulkan konflik.

\section{Persepsi dan Harapan Para Pihak yang Terlibat}

1. PT Surya Hutani Jaya (PT SHR)

Berikut ini adalah pandangan dari PT SHR sesuai dengan hasil wawancara dengan Bapak Rudi Sasgo, manager PT SHR. Berkaitan dengan kesepakatan dengan masyarakat di Desa Menamang Kiri pada tahun 2008, PT SHR bukan bermaksud untuk ingkar janji. Tapi fakta dilapangan, produksi yang diharapkan tidak sesuai dengan biaya produksi yang dikeluarkan sehingga tidak bisa memenuhi kesepakatan yang dibuat. Karena itu PT SHR menawarkan perubahan kesepakatan dengan perhitungan 43 ton/tahun. Ketika ditanya bagaimana perhitungan dari 43 ton/hektar terebut dan berapa hektar sesungguhnya lahan milik warga yang ditanami oleh PT SHR sebagai bagian dari kesepakatan yang dibuat, Rudi Sasgo tidak mampu menjelaskan.

Selanjutnya menurut PT SHR, masyarakat mulai menggarap lahan konsesi SHR yang berada di sekitar Desa Menamang Kiri. Karena itu, beberapa lokasi kebun kayu PT SHR yang berada di sekitar Desa Menamang Kiri sengaja tidak dipanen. PT SHR khawatir jika pohon-pohon tersebut ditumbang, akan mendorong warga untuk mengambil lahan tersebut. Berkaitan dengan kebun kemitraan yang pernah dibangun di tahun 2006, PT SHR menyatakan sudah tidak mungkin lagi untuk dipanen. Karena sebagian sudah ada yang ditumbang sendiri oleh warga untuk dijadikan kebun, dan selain itu, PT SHR kewalahan untuk mengurus areal yang mereka kelola selama ini

Berkaitan soal kebun warga Desa Menamang Kiri yang berada di dalam konsesi, PT SHR sengaja membiarkan karena tidak ingin berkonflik dengan warga. Mengenai makam keramat yang berada di dalam konsesi, PT SHR menyatakan akan menjaga makam tersebut karena bagian dari Nilai Konservasi Tinggi. PT SHR memiliki keinginan untuk menyelesaikan konflik dengan masyarakat Desa Menamang Kiri agar persoalan yang terjadi selama ini bisa diselesaikan dengan cara-cara yang baik. PT SHR bersedia untuk melakukan dialog dan musyawarah dengan masyarakat 
Desa Menamang Kiri tapi membutuhkan pihak-pihak yang netral untuk memfasilitasinya.

2. Masyarakat Desa Menamang Kiri

Persepsi masyarakat di dapatkan dari perangkat Desa Menamang Kiri dan beberapa orang warga dalam diskusi bersama yang dilakukan oleh penulis. Masyarakat menganggap PT SHR telah ingkar janji terhadap kesepakatan yang dibuat bersama pada tahun 2008. Beberapa upaya telah dilakukan masyarakat Desa Menamang Kiri dengan mendatangi kantor PT SHR tidak membuahkan hasil. Masyarakat menolak pembayaran sharing manfaat dengan perhitungan 43 ton/tahun karena kesepakatan yang dibuat tidak boleh diubah secara sepihak dan mereka pun tidak memahami dasar perhitungan 43 ton/tahun itu seperti apa?Masyarakat tetap menuntut pembayaran Rp 100 juta/tahun terhitung sejak tahun 2009 sampai 2013. Setelah itu dilunasi, masyarakat Desa Menamang Kiri bersedia untuk menegosiasikan ulang kesepakatan yang pernah dibuat.

Berkaitan dengan tidak boleh lagi ada tuntutan lahan sesuai dengan perjanjian di tahun 2008, masyarakat menyatakan bahwa lahan-lahan yang dibuka oleh warga saat ini tidak terkait dengan kesepakatan tersebut. Masyarakat menganggap PT SHR telah menggarap diluar konsesi dan masuk kedalam lahan dan kebun milik masyarakat. Jika pun masuk kedalam konsesi, masyarakat berharap agar lahan dan kebun tersebut tetap bisa dikelola oleh warga karena lahan dan kebun tersebut milik orang tua mereka yang diwariskan secara turun menurun. Selain itu, warga merasa tidak pernah menjual atau menyerahkan lahan dan kebun tersebut kepada PT SHR. Masyarakat memperkirakan ada sekitar 800 hektar lahan dan kebun yang masuk dalam konsesi. 300 hektar diantaranya sudah terdapat tanaman dan sisanya masih merupakan belukar dan perladangan.

Mengenai lahan mereka yang sempat dimitrakan dengan PT SHR, masyarakat Desa Menamang Kiri berharap agar PT SHR bersedia melakukan pemanenan. Dengan demikian, warga dapat mengelola lahan tersebut untuk ditanami dengan tanaman yang lain. Masyarakat merasa tidak memiliki sumber daya untuk melakukan penebangan sendiri, karena jumlah pohon yang begitu banyak. Masyarakat berharap agar konflik dengan PT SHR dapat diselesaikan. Untuk itu, masyarakat bersedia bermusyawarah 
dengan PT SHR untuk mencari solusi atas konflik yang terjadi selama ini. Masyarakat mengharapkan keterlibatan pihak ketiga yang netral untuk memediasi karena upaya negosiasi langsung dengan PT SRH tidak pernah membuahkan hasil.

3. Dinas kehutanan dan Perkebunan Pemerintah Daerah Kabupaten Kutai Kartanegara

Persepsi ini diwakili oleh Pak Yudi Arta dari Dinas Kehutanan dan Perkebunan Kabupaten Kutai Kartanegara. Berkaitan dengan konflik yang terjadi di Desa Menamang Kiri, pihak Pemerintah Daerah (Pemda) dapat diselesaikan dengan musyawarah. Pihak pemda pernah memfasilitasi pertemuan di Kantor Camat tahun 2013 yang lalu. Tapi pertemuan tersebut tidak membuahkan hasil karena masingmasing pihak bersikeras agar keinginannya diakomodir. Pemda tahu bahwa terdapat lahan dan kebun milik masyarakat Desa Menamang Kiri yang berada di dalam konsesi PT SRH dan melanggar hokum, jika mengacu pada UU No 41 Tahun 1999. Pihak Pemda Kabupaten Kutai Kartanegara belum berani mengambil sikap dan menyerahkan sepenuhnya persoalan tersebut kepada PT SRH.

4. Walhi Kalimantan Timur

Persepi Walhi Kalimantan Timur diwakili oleh Faturrozikhin sebagai Direktur Eksekutif Walhi Kalimantan Timur. Walhi menegaskan tentang pentingnya konflik ini segera diselesaikan karena kalu dibiarkan, akan berpotensi untuk menjadi konflik yang terbuka. Selain itu, PT SRH yang merupakan salah satu pemasok kayu APP, sudah sewajibnya menjalankan komitmen FCP yang sudah dinyatakan di tahun 2012 yang lalu. Komitmen tersebut salah satunya mengenai pentingnya upaya penyelesaian konflik dengan prinsip yang adil dan setara. Walhi Kalimantan Timur akan mendukung sepenuhnya upaya penyelesaian konflik melalui mediasi yang adil dan setara.

\section{Analisa Kebijakan}

Pengaturan mengenai ruang secara nasional baru dilakukan pada tahun awal tahun 1980-an, atau dapat dikatakan selama hampir 35 tahun sejak Indonesia merdeka tidak mempunyai konsep keruangan. Sektor kehutanan yang pada waktu itu masih di bawah Departemen Pertanian merupakan yang pertama kali mencetuskan konsep keruangan 
dalam bentuk Tata Guna Hutan Kesepakatan melalui SK Mentan N0 680/Kpts/Um/8/1981 tantang Pedoman Penatagunaan Hutan Kesepakatan.

TGHK pada hakekatnya hanya mengatur penataan untuk kawasan hutan, tetapi pada kenyataannya juga mengatur peruntukan lahan di luar sektor kehutanan. Dominasi kepentingan sektor kehutanan dalam TGHK tersebut tercermin dalam penentuan fungsi pemanfaatan, dimana sektor lain hanya dapat menggunakan lahan yang berstatus "Areal Penggunaan Lain (APL)" atau dikenal juga dengan istilah "Kawasan Budidaya Non Kehutanan (KBNK)". Keberadaan TGHK juga dapat dikatakan hampir meniadakan peranan BPN di Kaltim, karena menurut peraturan yang berlaku BPN tidak dapat "memasuki" wilayah teritori kehutanan.

Intensitas dan frekuensi konflik agraria hutan di Kaltim semakin meningkat setelah pemerintah mengeluarkan kebijakan pembangunan hutan tanaman industri (HTI) melalui SK Menhut No. 320/Kpts-II/1988 tentang Pembangunan Hutan Tanaman Industri dan PP No 7 tahun 1990 tentang Hak Pengusahaan Hutan Tanaman Industri (HPHTI). Seperti halnya HPH pembangunan HTI di Kaltim dilakukan oleh pengusaha-pengusaha besar melalui pemberian HPHTI, baik melalui pola swasta murni, patungan dengan BUMN maupun pola HTI yang dibarengi dengan program transmigrasi.

Dengan adanya pembangunan HTI ini, spektrum konflik menjadi bertambah luas tidak hanya masalah hilangnya akses pemanfaatan hasil hutan tetapi juga menutup akses penguasaan tanah komunitas lokal secara total (Abdurahman dan Wentze, 1997). Beberapa faktor yang membuat komunitas lokal 'lebih terancam' dengan sistem pengusahaan HTI sebagai berikut : (1) konsesi HTI diarahkan pada areal yang dianggap kurang produktif (semak belukar) yang pada kenyataannya merupakan lahan cadangan bagi komunitas lokal yang diberakan untuk rotasi mendatang, (2) sistem pengusahaan HTI menuntut dilakukannya land clearing total areal hutan dan menggantikannya dengan tanaman sejenis (monokultur) sehingga banyak sekali keanekaragaman hayati hilang yang merupakan sumber penghidupan komunitas lokal, (3) kemudian juga kawasan-kawasan hutan yang 'dikeramatkan' baik untuk pemujaan maupun kuburan leluhur serta kebunkebun rotan dan buah ikut di bersihkan dan (4) khusus untuk pola transmigrasi, komunitas lokal menjadi kehilangan lahan secara mutlak karena sebagian wilayahnya diperuntukan untuk transmigran yang langsung mempunyai kekuatan hukum kepemilikan melalui 
sertifikat. Sebagai catatan, hingga tahun 1995 HPHTI di Kaltim berjumlah 50 perusahaan dengan luas areal konsesi sekitar 1,6 juta ha.

Jika melihat kasus konflik antara masyarakat Desa Menamang Kiri dengan PT SHR, konflik dimulai ketika pemerintah mengeluarkan izin konsesi dan meniadakan sistem tenurial tradisional masyarakat yang terkena dampak dari pembangunan industry tersebut. Faktanya, konflik-konflik yang terjadi di daerah-daerah sangat erat kaitannya dengan kebijakan umum dari Pemerintah Pusat. Kebijakan yang hanya dilandasi oleh keinginan untuk memperbesar jumlah invesatsi berimplikasi pada ketimpangan penguasaan lahan dan hutan oleh korporasi. Hal ini dapat dilihat dari ketimpangan pemberian izin konsesi kepada perusahaan HTI. Kementrian Kehutanan pada tahun 2011 tercatat telah memberikan izin IUPHHK-HTI Seluas 34,47 juta Ha atau $26 \%$ dari total kawasan hutan (Baplan-Kemenhut 2011). Sementara itu, pemberian izin pengelolaan Kehutanan Masyarakat (Hutan Kemasyarakatan/HKm, Hutan Tanaman Rakyat/HTR, Hutan Desa dan Hutan Adat) berdasarkan izin Bupati/Gubernur hanya seluas 131.209.34 hektar atau kurang dari $1 \%$ total kawasan hutan dari rencana semula seluas 1.210.815 hektar di tahun 2010 (Santosa and Silalahi,2011).

Dalam konteks kebijakan Corporate Sosial Response (CSR), PT SHR selama ini sangat minim memberikan bantuan. Kontribusi yang diberikan kepada Desa Menamang Kiri hanya terbatas pada:

1. Pemberian Atap Masjid

2. Pengerasan Jalan Kampung 4 kilometer

3. Pembuatan jalan baru menuju pemakaman Keramat (Ahmad Abdul Fikar)

4. Tenaga Kerja (2 orang)

Bantuan yang diberikan PT Surya Hutani Jaya tersebut menurut Jainuddin (Mantan Kepala Desa Menamang Kiri), pemaksaan dari masyarakat. Karena pada saat itu pihak perusahaan sedang melakukan pembuatan jalan poros dan saat itu lah masyarakat Desa Menamang Kiri memaksa truk-trukk yang membawa sertukil dipaksa masuk ke jalan menuju desa dan menyebarkan sertukil tersebut ke jalan menuju makam.

Pada tanggal 11 Februari 2013, Asian Pulp Paper (APP) mengeluarkan Kebijakan Konservasi Hutan atau dikenal juga dengan sebutan Forest conservation Policy yang berisi tentang enam komitmen APP dalam rangka menwujudkan praktek hutan yang berkelanjutan. Kebijakan ini berlaku bagi seluruh pemasok kayu APP di Indonesia, seluruh 
serat kayu yang berasal dari Indonesia dan dipergunakan oleh pabrik APP dan juga untuk ekspansi APP di masa depan. Komitmen tentang keterlibatan sosial dan masyarakat dinyatakan; Untuk menghindari maupun menyelesaikan konflik sosial di keseluruhan rantai pasokannya, APP akan secara aktif meminta dan mengikut sertakan saran dan masukan dari berbagai pemangku kepentingan termasuk masyarakat sipil, untuk menerapkan prinsip-prinsip berikut :

1. Free, Prior and Informed Consent (FPIC) dari masyarakat asli dan komunitas lokal

2. Penanganan keluhan yang bertanggung jawab

3. Pemecahan konflik yang bertanggung jawab

4. Dialog yang terbuka dan konstruktif dengan para pemangku kepentingan lokal, nasional dan internasional

5. Program pengembangan dan pemberdayaan masyarakat

6. Penghormatan terhadap hak asasi manusia

7. Mengakui dan menghormati hak-hak karyawannya

8. Kepatuhan terhadap hukum, prinsip dan kriteria sertifikasi bertaraf internasional yang relevan

Prinsip yang tertuang dalam komitmen sosial dan keterlibatan masyarakat memberikan peluang yang begitu besar dalam upaya penyelesaian konflik di Desa Menamang Kiri. Beberapa praktek PT SHR yang mengingkari kesepakatan dan secara sepihak telah merubah kesepakatan dalam perjanjian sharing manfaat tentu saja tidak sesuai dengan prinsip FPIC. Praktek menghindar atau membiarkan konflik yang terjadi, tentu saja tidak sesuai dengan prinsip pemecahan konflik yang bertanggung jawab. Sebagai perusahaan yang juga telah mendapatkan sertifikat PHPL, penerapan komitmen sesuai dengan FCP menjadi salah satu faktor yang cukup penting untuk memulai dialog dengan masyarakat dalam penyelesaian konflik.

\section{PENUTUP}

Dengan situasi tersebut, maka rekomendasi penyelesaian yang bisa digunakan dalam konflik ini adalah :

1. Pada tahap awal, perlu dilakukan pemetaan terhadap wilayah kelola masyarakat, terutama wilayah-wilayah yang menjadi obyek sengketa.

2. Perlu dilakukan pendekatan dan pemahaman kepada pemerintah dan perusahaan tentang pentingnya upaya untuk segera menyelesaikan konflik yang terjadi di Desa Menamang Kiri.

3. Melihat posisi dan gaya bersengketa masing-masing pihak yang saling menghindar tapi disisi yang lain bersedia untuk melakukan dialog, maka mediasi menjadi 
pilihan model penyelesaian konflik. Tentu saja pra kondisi-pra kondisi harus dilakukan baik di tingkat masyarakat maupun di tingkat perusahaan.

\section{DAFTAR PUSTAKA}

\section{Buku Teks:}

Abdurrahman dan Sondra Wentzel. 1997. Konsep Untuk Menyelesaikan Masalah Status Tanah Masyarakat di Kawasan Hutan Pada Areal HPH dan HPHTI di Propinsi Kalimantan Timur. Dokumen SFMP-GTZ No. 11.

Alo,lili. 2005. Prasangka dan Konflik. Yogyakarta

Fisher, Simon, dkk. 2001. Mengelola Konflik : Keterampilan dan Strategi Untuk Bertindak, Cetakan Pertama, Alih Bahasa S.N. Kartikasari, dkk, The British Counsil, Indonesia. Jakarta.

Galudra,Gamma. 2014. Rapid Land Tenure Assessment: Panduan Ringkas untuk Memahami Klaim Tenurial, bahan presentasi pada Pelatihan Perangkat Analisis Land Tenure dan Penanganan Konflik dalam Pengelolaan KPH Angkatan, 26/08/2014.

Kementerian kehutanan. 2014. Statistik kehutanan tahun 2013. Jakarta.

Konsorsium Pembaharuan Agraria (KPA). 2013. Laporan Akhit Tahun 2013 KPA: Warisan Buruk Masalah Agraria di Bawah Kekuasaan SBY. Jakarta.

Koalisi Anti Mafia Hutan. 2014. Catatan Kritis Koalisi LSM terhadap Legalits dan Kelestarian Hutan Indonesia: studi Indpenden Terhadap Sertifikasi SVLK.

Profil Kehutanan Kalimantan Timur. 2012.

Santosa, A, And Silalahi, M. 2011 Kajian Kebijakan Kehutanan Masyarakat dan Kesiapannya dalam REDD+. Forum Komunikasi Kehutanan Masyarakat. Bogor.

Suhendar, E dan Winarni. 1998. Petani dan Konflik Agraria. AKATIGA. Bandung.

Trustindo Prima Karya. 2013. Resume Hasil Penilaian Kinerja PHPL PT Surya Hutani Jaya.

\section{Peraturan Undang-Undang :}

Undang-undang Nomor 41 Tahun 1999 Tentang Kehutanan

\section{Internet :}

Lihat http://geodata-cso.org/baca/8/konflik-sumber-daya-alam---agraria-di-kalimantan

Kompas, Sabtu 27 Januari 1996 "Danrem Aji Surya Natakusuma: Kehadiran ABRI Mencegah Konflik yang Lebih Gawat"

Kompas, Kamis 25 Januari 1996 "Kapuspen ABRI: ABRI akan selidiki kasus kutai” 